\title{
Mechanical and dry sliding wear behavior of LM6/cenosphere composites
}

\author{
Tanusree Bera $^{1}$, S.K. Acharya ${ }^{1}$, Goutam Sutradhar ${ }^{2}$ \\ ${ }^{I^{*}}$ Department of Mechanical Engineering, National Institute of Technology, Rourkela, INDIA \\ ${ }^{2}$ National Institute of Technology, Manipur, INDIA \\ *Corresponding Author: e-mail: tanusree.bera@gmail.com, Tel +91-9778574700
}

\begin{abstract}
Cenosphere particles are potential discontinuous dispersoids used in metal matrix composites, since they are low-cost and lowdensity reinforcement available in large quantities as a waste by-product in thermal power plants.It helps in decreasing the density of the composites and increases the mechanical as well as the tribological behavior of the composites.In the present work, the influence of cenosphere on the microstructure, mechanical properties and dry sliding wear behavior of Al-Si12 matrix alloy was investigated. Wear tests were performed on the pin-on-disc wear tester at $0.5235,1.0472,1.5708$ and $2.0944 \mathrm{~m} / \mathrm{s}$ sliding velocity under loads of $5,10,15$ and $20 \mathrm{~N}$. The results revealed the homogeneous distribution of the cenosphere particles on the matrix alloy. The mechanical properties improved with increasing of cenosphere particles. The coefficient of friction of the matrix alloy and composites reduced and wear rate improved with increase in the load. Scanning electron microscopy (SEM) analysis indicated that specimens were worn out by abrasive, adhesive, and delamination wear mechanism.
\end{abstract}

Keywords:Al-Si12 matrix alloy, Cenosphere, Pin-on-disc wear tester, Dry sliding wear, Abrasive wear mechanism.

DOI: http://dx.doi.org/10.4314/ijest.v11i1.1

\section{Introduction}

In the last few years, the metal matrix composites (MMCs) have emerged as the best material in the various industries due to its novel properties. Increasingly, MMCs are being used to replace the conventional materials in many applications, especially in the automobile industries (Rohatgi, 1994). But still, due to the cost factor, the MMCs are more expensive than the conventional materials. The cost factor limited the usage of the MMCs in various fields. Cost reductions can be achieved by the use of the less expensive reinforcements and simpler fabrication methods. The search of cheaper and inexpensive reinforcement has led to the use of cenosphere particles.

A cenosphere is a lightweight, inert, hollow sphere made largely of silica and alumina and filled with air or inert gas, typically produced as a byproduct of coal combustion at thermal power plants (https://en.wikipedia.org/wiki/cenosphere). Thus the addition of the waste cenosphere particles in aluminum MMCs will reduce the cost of the aluminum products.

Al-Si12 matrix alloy (http://www.cast-alloys.com/products/lm-chart.htm) has good casting characteristics. The alloy has good fluidity and hot tearing properties that make to produce thick and thin casting sections. It has a high strength which can be used for structural components in the automobile industry.

Casting is one of the most economical methods for fabrication of MMCs (Ghomashchi and Vikhrov, 2000). However, there are many drawbacks in conventional castings, such as porosity, hot tears, A and V segregates (Aldas and Mat, 2005). To overcome all these drawbacks, new casting techniques have been introduced. Among other casting methods, squeeze casting has more potential to create less defective cast components (Hashimet al., 2001).

Extensive work has been done on Al MMCs by squeeze casting route. Many researchers worked on the various $\mathrm{Al}$ alloys MMCs. For instance, (Sukumaranet al., 2008) worked on the Al 2024 alloy with $10 \%$ of silicon carbide particles fabricated by squeeze casting method. Authors described the effect of squeeze pressure during solidification. They concluded that with a pressure of $100 \mathrm{MPa}$, a very fine microstructure was obtained with minimum casting defects. (Onatet al., 2008) and (Onat, 2010) 
worked on the $\mathrm{Al}-4.5 \mathrm{Cu}-3 \mathrm{Mg}$ alloy with various volume \% of $\mathrm{SiC}$ particles through the squeeze casting techniques. The researchers found that the hardness, tensile strength of the matrix alloy increased by squeeze casting. The squeeze castings resulted in fine microstructural cast component with minimum casting defects and increased in the tribological wear properties.

Sun et al. (2014) fabricated Aluminum Matrix Fly Ash (AMFA) Cenosphere composites using the stir casting technique and studied the effect of process parameters on composites. They also found that tensile strengths improved maximally by $50 \%$ when the cenosphere content is $13 \mathrm{wt} \%$. This type of composite is difficult to fabricate because of the abrasive nature of the alumina reinforcement. The wear resistance of the Al 7075 reinforced with B4C composite increases with the increasing amount of B4C particles (Baradeswaran and Perumal, 2013).(Prabu et al., 2006) studied the distribution of particles in a metal matrix (aluminium alloy-silicon carbide) based on stirring speed and stirring time and observed that increase in stirring speed and stirring time results in a homogenous distribution of the particles.(Lashgari et al., 2009) examined the influence of strontium on improving wear resistance in aluminium boron carbide stir cast composites with $10 \%$ reinforcement. They proved that adding strontium to aluminium boron carbide composites increase wear resistance. The addition of boron carbide in Al-Si-Mg alloy matrix yield improved mechanical properties. The boron carbide particles were uniformly dispersed in the aluminium matrix (Canute and Majumder, 2018). Kalaiselvan et al. (2011) examined the effect of boron carbide particles $(20 \mu \mathrm{m})$ with varying weight fractions $(2 \%, 4 \%, 6 \%$, and $8 \%)$ in A359 alloy through stir casting method. The experimental results revealed that the A359/B4C/8p composites have high hardness and tensile strength.

So far from the earlier studies, it has been observed that studies on squeeze casting were carried out in cast aluminum alloys such as Al6061, AA603, Al2024, Al-Si8Cu3Fe, Al-Si7Mg, A357, A535 and A7010 (Ghomashchi and Vikhrov, 2000; Yue and Chadwick, 1996 and Sukaramet al., 2004). However, no work has been reported on the Al-Si12 matrix alloy with cenosphere by squeeze casting process. The present investigation is based on the microstructural studies, mechanical properties and tribological behavior of both the Al-Si12 matrix alloy and Al-Si12/cenosphere composites.

\section{Experimental procedure}

\subsection{Materials:}

In the present study Al-Si12 alloy is used as matrix it consists of $\mathrm{Cu}-0.1 \%, \mathrm{Mg}-0.1 \%, \mathrm{Si}-11.8, \mathrm{Fe}-0.6 \%, \mathrm{Mn}-0.5 \%, \mathrm{Ni}-0.1 \%, \mathrm{Zn}-$ $0.1 \%, \mathrm{~Pb}-0.1 \%, \mathrm{Ti}-0.2 \%, \mathrm{Sb}-0.05 \%$, Al-remainder. The reinforcement used in this study is cenosphere, procured from National Power Engineers, Kolkata, India. The size of the cenosphere particles are in the range of 30-200 m, and the density is $0.6 \mathrm{~g} / \mathrm{cm}^{3}$.

\subsection{Composite Fabrication:}

The fabrication process of the composites may be found elsewhere (Beraet al., 2017).

\subsection{Experimental Tests:}

The optical microstructure study is carried out in the ZEISS optical microscope (model- AX10). The samples are first polished in the belt polishing in order to get the required dimension of the samples then the samples are polished with the emery polishing paper with grades $1 / 0,2 / 0,3 / 0$, and $4 / 0$ respectively for 1-2 hours after that the samples are polished in the cloth polishing for 1-2 hours and finally polished in the diamond polishing with $3 \mathrm{~m}$ diamond paste, until the scratches are removed from the required surface of the samples and the mirror-like surface obtained.

The hardness of the composites is measured in a LECO microhardness tester (Model -LM 248AT) with a Vickers diamond indenter under a load of $500 \mathrm{gf}$. The dwell time was $15 \mathrm{~s}$, and the speed of indentation is $50 \mu \mathrm{m} / \mathrm{s}$. The mean of at least five tests is taken for each sample.

The theoretical density of the composites is measured using equation may be elsewhere (Agarwalet al., 2017). The experimental density is determined with the Archimedes principle.

Table 1.Density and porosity of the matrix alloy and composites.

\begin{tabular}{|c|c|c|c|}
\hline Sample Name & $\begin{array}{c}\text { Theoretical } \\
\text { density }\left(\rho_{T}\right)\end{array}$ & $\begin{array}{c}\text { Experimental } \\
\text { Density }\left(\rho_{E}\right)\end{array}$ & Porosity (\%) \\
\hline LM6 alloy & 2.648 & 2.644 & 0.151 \\
\hline $5 \mathrm{wt} \% \mathrm{c} / \mathrm{s}$ & 2.655 & 2.642 & 0.489 \\
\hline $7.5 \mathrm{wt} \% \mathrm{c} / \mathrm{s}$ & 2.662 & 2.639 & 0.864 \\
\hline $10 \mathrm{wt} . \% \mathrm{c} / \mathrm{s}$ & 2.669 & 2.635 & 1.273 \\
\hline $12.5 \mathrm{wt} \% \mathrm{c} / \mathrm{s}$ & 2.675 & 2.625 & 1.869 \\
\hline
\end{tabular}

The dry sliding wear tests are carried out by pin-on-disc wear tester (Figure1). The pin-on-disc wear tester details may be found elsewhere (Bera and Acharya, 2017). The wear tests are carried under a dry condition at ambient condition. The dry sliding wear test is performed on a steel disc (EN 31) having of $120 \mathrm{~mm}$, and a thickness of $8 \mathrm{~mm}$ is used as a counter surface. The average 
roughness $(\mathrm{Ra} \%)$ of the steel disc is $1.2 \mu \mathrm{m}$. The test specimens are cylindrical pin shape with a dimension of $10 \mathrm{~mm}$ of diameter and $26 \mathrm{~mm}$ of height. The pins are made to slide on the steel disc with the various parameters as given in Table 2. Further details of the test details may be found elsewhere (Bera and Acharya, 2017). The wear rate and coefficient of friction values are calculated using ASTM formulas. The surface morphology of the worn out samples is performed on a SEM.

Table2. Parameters of the dry sliding wear tests of the matrix alloy and composites

\begin{tabular}{|c|c|c|}
\hline Test parameters & Units & Values \\
\hline wt.\% c/s & $\%$ & $5,7.5,10,12.5$ \\
\hline Load & $\mathrm{N}$ & $5,10,15,20$ \\
\hline Track radius & $\mathrm{mm}$ & 50 \\
\hline Sliding velocity & $\mathrm{m} / \mathrm{s}$ & $0.5235,1.0472,1.5708,2.0944$ \\
\hline Temperature & ${ }^{\circ} \mathrm{C}$ & Ambient \\
\hline
\end{tabular}

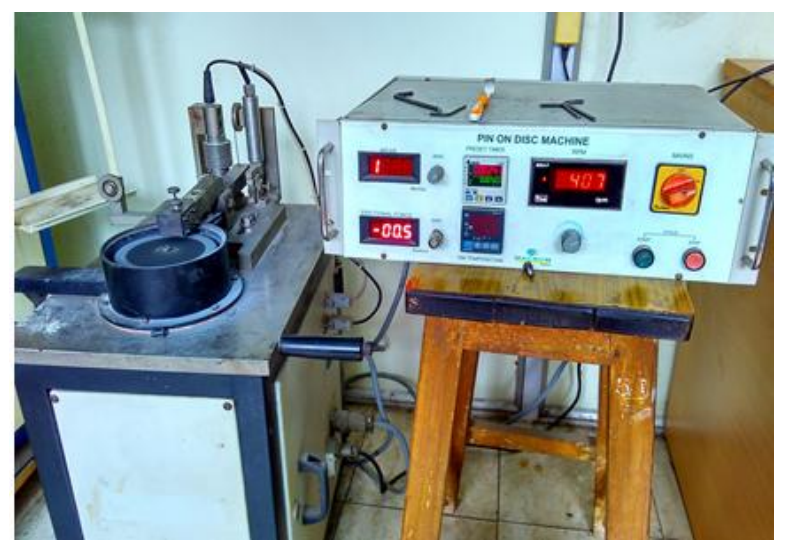

Figure 1. Experimental set up of pin-on-disc wear tester.

\section{Results and discussion}

\subsection{Effect of cenosphere on hardness:}

The hardness results of Al-Si12/cenosphere composites are given in Table 3. As can be seen in Table 3, cenosphere particle increases the hardness of the composites. The hardness of the composites increased due to the uniform distribution of the cenosphere particles on the Al-Si12 alloy matrix. The increase in hardness of the composites can also by the load transfer effect, thermal mismatch of the reinforcing particles and matrix. Due to this when load applied on materials the load transfer from softer matrix to harder particle so hardness increases. The hardness increases with the Hall-Petch theory and Orowon mechanism.

Table 3.Hardness value of the matrix alloy and composites.

\begin{tabular}{|c|c|}
\hline Sample Name & Hardness \\
\hline LM6 alloy & 69.12 \\
\hline $5 \mathrm{wt} . \% \mathrm{c} / \mathrm{s}$ & 74.24 \\
\hline $7.5 \mathrm{wt} . \% \mathrm{c} / \mathrm{s}$ & 79.61 \\
\hline $10 \mathrm{wt} \% \mathrm{c} / \mathrm{s}$ & 84.25 \\
\hline $12.5 \mathrm{wt} . \% \mathrm{c} / \mathrm{s}$ & 90.10 \\
\hline
\end{tabular}

\subsection{Effect of cenosphere on density:}

The theoretical and experimental densities of the composite along with the corresponding porosity are presented in Table 1. It is observed from the table 1 that the actual and obtained density values are different. It also reported that the porosity of the composites increased with the addition of reinforcing particles. The similar results have been reported by various authors such as (Hanumaanth and Irons, 1993; Kok, 2000, and Ghosh and Ray, 1988). The variation in the results is due to the difference in the size and shape of the reinforcement and matrix, and entrapment of air bubbles during the stirring of the molten material inside the furnace. 
Table 4.Mechanical properties of the matrix alloy and composites.

\begin{tabular}{|c|c|c|}
\hline Sample Name & $\begin{array}{c}\text { Tensile strength } \\
(\mathbf{M P a})\end{array}$ & $\begin{array}{c}\text { Young's } \\
\text { Modulus } \\
(\mathbf{G P a})\end{array}$ \\
\hline LM6 alloy & 112 & 55 \\
\hline $5 \mathrm{wt} \% \mathrm{c} / \mathrm{s}$ & 120 & 62 \\
\hline $7.5 \mathrm{wt} \% \mathrm{c} / \mathrm{s}$ & 130 & 67 \\
\hline $10 \mathrm{wt} . \% \mathrm{c} / \mathrm{s}$ & 142 & 73 \\
\hline $12.5 \mathrm{wt} \% \mathrm{c} / \mathrm{s}$ & 155 & 81 \\
\hline
\end{tabular}

\subsection{Effect of cenosphere on Tensile strength:}

The Tensile strength of the composites is presented in Table 4. From Table 4 it is observed that tensile strength and Young's modulus of elasticity of the composite increases as the cenosphere content increases. The $12.5 \mathrm{wt}$ \% composites have the higher tensile strength and Young's modulus of elasticity than other composites.

\subsection{Effect of cenosphere on microstructure:}

Figure 2 represents microstructures of Al-Si12 matrix alloy and Al-Si12 /cenosphere composite. It can be seen that microstructure of composite (Figure 2a and b) consists of primary silicon, eutectic silicon, alpha aluminum ( $\alpha-\mathrm{Al}$ ) and cenosphere particles. The SEM micrograph shows the uniform distribution of cenosphere particles. One of the very important factors in the Casting of the materials is the cooling rate. In sand casting, the cooling rate is slow, results in the segregation of the reinforcing particles at the interdendritic zone. But in squeeze casting cooling rate is high, resulting in uniform distribution of the reinforcing particles throughout the matrix (Sukumaranet al., 2008, and Onat, 2010). In the present study, as solidification rate in squeeze cast composites was very high, Therefore agglomerations have not been observed.
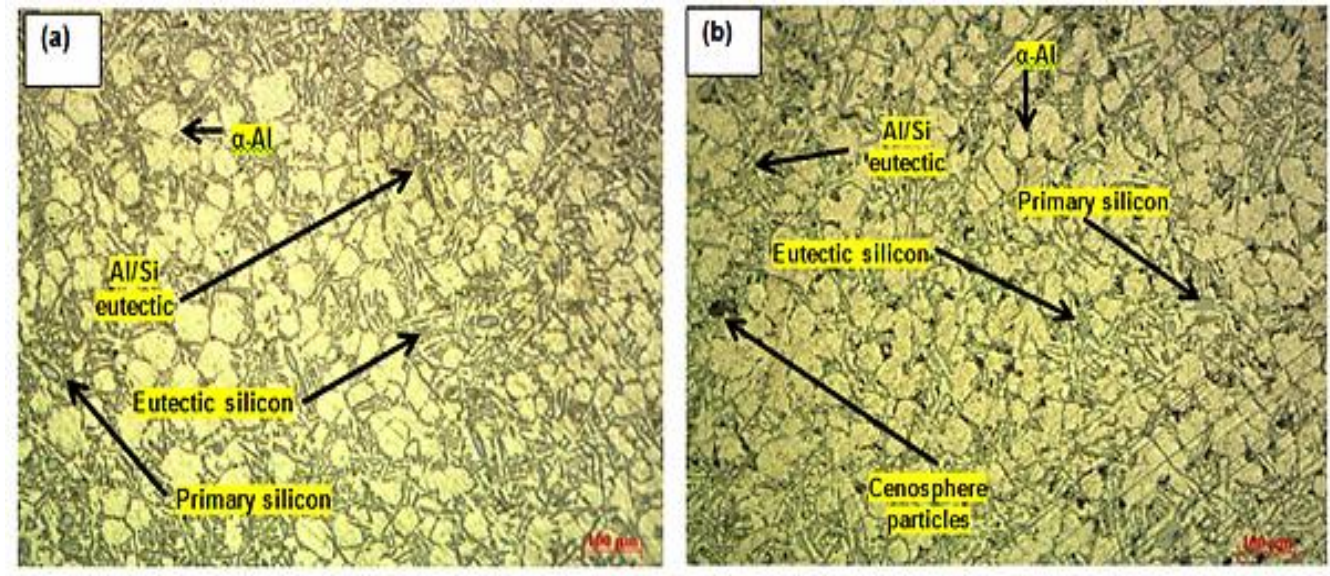

Figure 2.Optical micrographs of (a) Al-Si12 matrix alloy (b) Al-Si 12/cenosphere composite

\subsection{Influence of applied load on coefficient of friction:}

Figure 3 shows the variation of the coefficient of friction of the Al-Si12 matrix alloy and composites with load at $0.5235 \mathrm{~m} / \mathrm{s}$ sliding velocity. It can be seen that the coefficient of friction of the matrix alloy and composites decreased with increasing load. The friction coefficient decreases with increase in the wt. \% c/s. Rana et al., (1989) studied the friction coefficient existing between an $\mathrm{Al}-1.5 \% \mathrm{Mg}$ alloy reinforced with $\mathrm{SiCp}$. They concluded that the friction coefficient decreased with an increase in the volume fraction of $\mathrm{SiC}$ particles. Saka et al., (1985) examined friction and wear in $\mathrm{Cu}$ reinforced with $\mathrm{Al}_{2} \mathrm{O}_{3}$ particles. They revealed that the friction coefficient decreased with increase in alumina content. A similar observation was reported by Zhang et al., (1994). The decrease in coefficient of friction with the increase in load can be due to an increase in load, the temperature of the contact surface increases and softens the surface of the pin. So, the friction coefficient decreases. There may be another reason that when the load increases, more wear of pin surface occurs, and the wear debris stuck in between pin and counter surface and acts as roller ball. Therefore, the coefficient of friction decreases. 


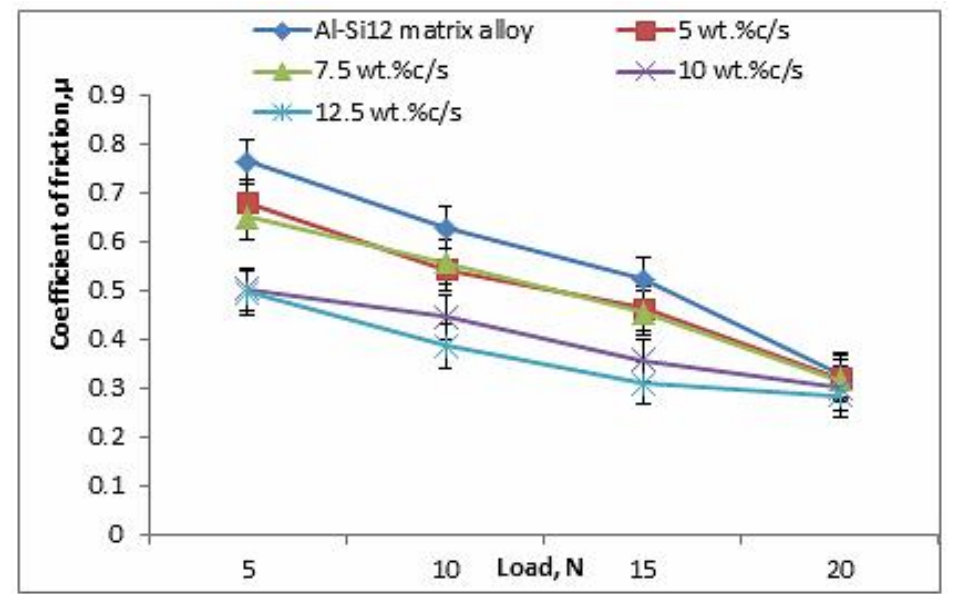

Figure 3.Variations in coefficient of friction with loads

3.6 Influence of applied load on Wear rate:

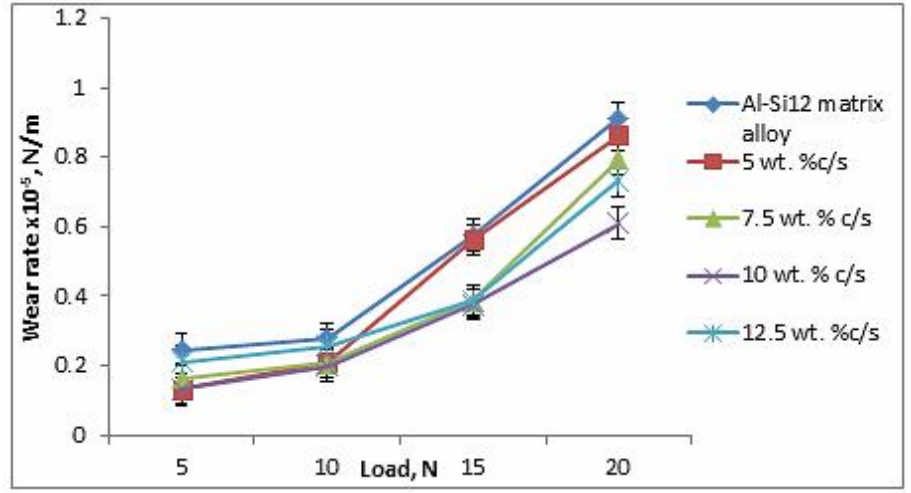

Figure 4. Variations in wear rate with loads

Figure 4 presents the variation of wear rate of matrix alloy and composites with load at $1.0472 \mathrm{~m} / \mathrm{s}$ sliding velocity. The wear rate increased with the increase in the load. This is an agreement with studies of some researchers (Basavarajappaet al., 2006; Sahin and Ozdin, 2008, and Das et al., 2008). A similar observation was examined by Alpaset al., (1992), and Moustafa, (1995). This can be attributed due to following reasons-first one- At low load, mild wear was examined, but as the load increased beyond $10 \mathrm{~N}$, the severe wear occurred. The severe wear is characterized by huge surface damage and results in the production of large wear debris (Figure 7a). Huge noise and vibration are detected during the process, and the transfer of the specimen material to the disc is observed. The second one- During the initial stage of abrasion, abrasive is in contact with the matrix, has less hardness as compared to angular silica sand (abrasive) particles. At that particular instance, the ratio $\mathrm{Ha}$ (hardness of the abrasive particle)/Hs (hardness of the surface) is much more than unity, resulting in severe matrix damage and the rate of material removal is very high. Thus, the specific wear rate is more. When the load increases, cenosphere particles get in contact with abrasive particles, $\mathrm{Ha} / \mathrm{Hs}$ ratio is a little more than unity; as a result, cenosphere particles provide better resistance to the process of abrasion and reduce the wear rate.

\subsection{Influence of Sliding velocity on Specific wear rate:}

Figure 5 represents the variation of SWR of matrix alloy and composites with sliding velocity. The SWR first decreased with increasing sliding speed up to $1.5708 \mathrm{~m} / \mathrm{s}$ and then increased with further increasing sliding velocity. This is because, at slow sliding velocity, the sliding surface is covered with oxide like mechanically mixed layer (MML) formed at the sliding interface and minimized direct metallic contacts. This resulted in a lower wear rate. At very high-velocity thermal softening of the matrix and localized melting on the interface, surfaces are reported. This causes the breakdown of the MML and allows more direct metallic contact during sliding, and cenosphere particles became dislodged, and suddenly huge wear resulted.

The same results were found by many researchers (Deusiset al., 1996; Wang and Rack, 1991; Lim et al., 1992, and Kwok et al., 1994), and author Subramanian, (1991) investigated the dry sliding wear behavior of an Al-12.3\%Si alloy. He concluded that the wear rate of the alloy decreased with increasing sliding speed up to a critical speed, beyond which it increased. 


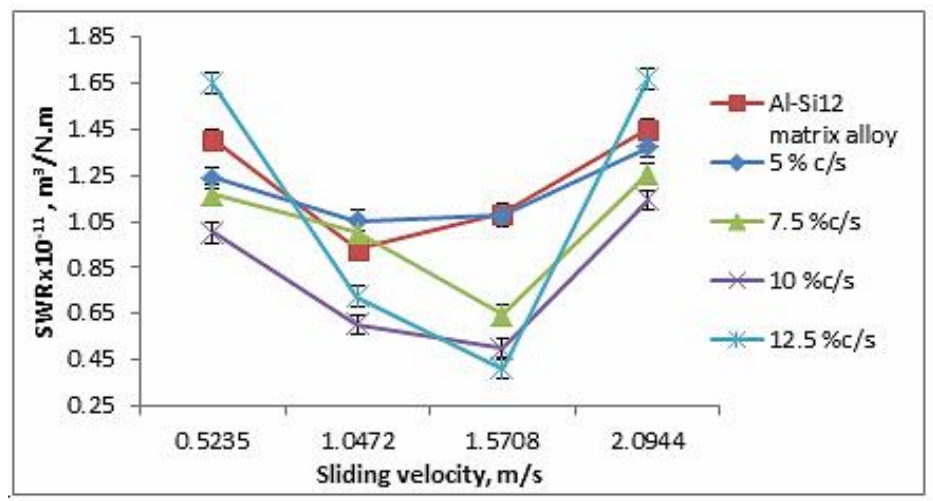

Figure 5. Variation in SWR as a function of sliding velocity

\subsection{Morphology of the worn surface:}

Figure 6-9 shows the worn surface morphology of the matrix and composites at different load. The sliding direction for all SEM morphology is represented by an arrow.

At low load, the SEM micrograph of matrix alloy (Figure 6a) consists of grooves, smaller and bigger size of wear debris. The grooves are of varying sizes, mainly wide and deep. The wear debris is accumulated along the edge of the grooves. The grooves are parallel to the sliding direction. But for the same load, the worn morphology of the composite (Figure 6b) contains grooves with no wear debris. These grooves are very shallow and narrow. The wear rate of the matrix alloy is more than composite at the same load. This is due to the Archard law (Archard et al., 1953), According to the law, the wear rate of the material inversely proportional to the hardness of the material. The composite has a higher hardness than matrix alloy due to cenosphere particles.

At a load of $10 \mathrm{~N}$, the morphology of the matrix (Figure 7a) consists multiple of small wear debris along the sliding direction of the grooves. It is shown in Figure 7(b) that the grooves are very wide and deep with some craters. The grooves reveal the presence of abrasive wear mechanism and the craters resemble the delamination. The delamination wear mechanism is more prominent at higher load. It results in craters and propagation of cracks on the wear surface (Figure 7b, 8-9).

At a load of $15 \mathrm{~N}$, the morphology of the matrix (Figure 8a) has very long and wide crack along the sliding direction with wide grooves. This deep crack is due to breakage of the matrix during sliding. When we observe the Figure 8(b), it is clearly seen that the worn composite surface has shallow grooves with a small transfer of material and crater. The transfer of material reveals the adhesive wear.

At a higher load of $20 \mathrm{~N}$, the worn surface of Figure (9a and b) has very deep and wide craters with a huge transfer of material. This is due to adhesive and delamination wear mechanism. The adhesive wear is the transfer of the material from the interface surfaces during the relative motion due to bonding between the interface contacting surfaces. The wear debris comes out from the wearing surface resulted in the hard protective layer called as tribolayer (Jiang et al., 1995). This layer is also known as MML. At lower load, the tribology is stable, but when load increases the thermal softening of the matrix causes a breakdown in the tribolayer, resulting in more wear rate.
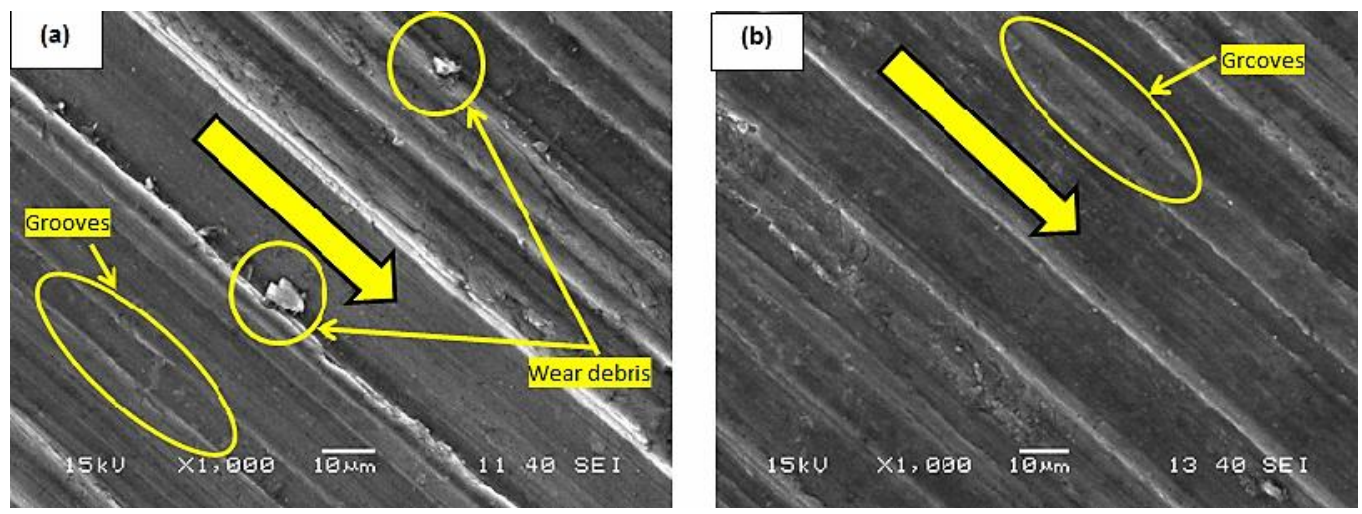

Figure 6.SEM morphology of (a) matrix alloy (b) composite at $5 \mathrm{~N}$ load and $0.5235 \mathrm{~m} / \mathrm{s}$ sliding velocity 

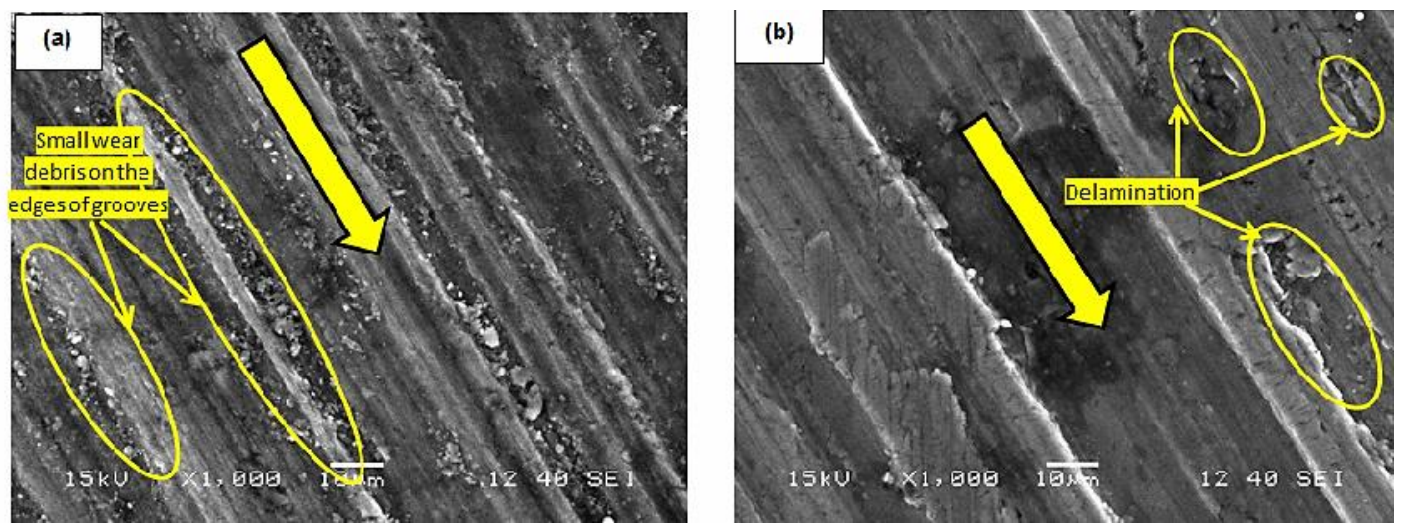

Figure 7.SEM morphology of (a) matrix alloy (b) composite at $10 \mathrm{~N}$ load and $1.0472 \mathrm{~m} / \mathrm{s}$ sliding velocity
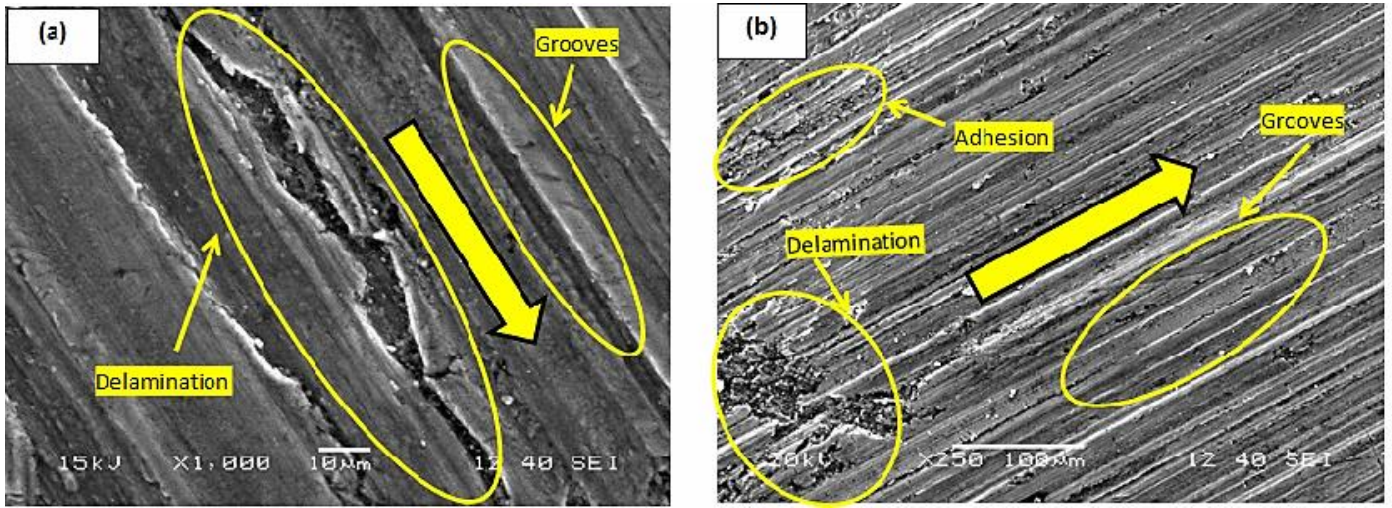

Figure 8.SEM morphology of (a) matrix alloy (b) composite at $15 \mathrm{~N}$ load and $1.5708 \mathrm{~m} / \mathrm{s}$ sliding velocity
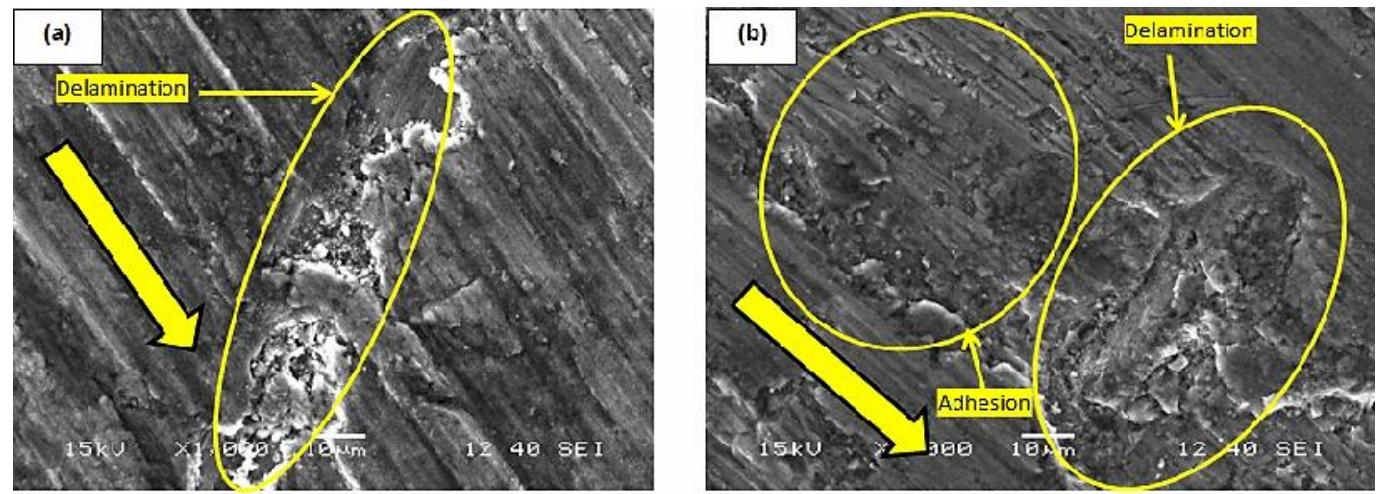

Figure 9.SEM morphology of (a) matrix alloy (b) composite at $20 \mathrm{~N}$ load and $2.0944 \mathrm{~m} / \mathrm{s}$ sliding velocity

\section{Conclusions}

The Al-Si12/cenosphere composites can be successfully fabricated by Squeeze casting method. The cenosphere particles are uniformly distributed in the matrix alloy with no agglomeration. Thereare no segregations of reinforced particles. Microstructures of the composites contain primary phase and eutectic regions. The squeeze casting process resulted in refining microstructure in squeeze cast matrix alloy and composites. The hardness of the Al-Si12 matrix alloy increases with the addition of the cenosphere. The hardness value increases from 69.12 to $90.10 \mathrm{VHN}$. The porosity increases with the increase in the cenosphere content in the Al-Si12 matrix alloy. The Al-Si12 matrix alloy has the minimum porosity of $0.151 \%$ and the $12.5 \mathrm{wt} \% \mathrm{c} / \mathrm{s}$ has the highest porosity of $1.869 \%$. The coefficient of friction of the matrix alloy and composites decreased with increase in load. The Al-Si12 matrix alloy has the highest friction coefficient as (0.8-0.4) and composite with $12.5 \mathrm{wt}$. \% c/s has the lowest with (0.5-0.3).The wear rate increases with increase in the load. The matrix alloy has the highest wear rate of $0.9 \times 10^{-5} \mathrm{~N} / \mathrm{m}$, whereas the wear rate of 
$10 \mathrm{wt} . \% \mathrm{c} / \mathrm{s}$ is $0.55 \times 10^{-5} \mathrm{~N} / \mathrm{m}$. The SWR first decreased with increasing sliding speed up to $1.5708 \mathrm{~m} / \mathrm{s}$ and then increased with further increasing sliding velocity. The SEM analyses of the worn out samples indicates the presence of abrasive wear mechanism, adhesive wear mechanism, and delamination wear mechanism.

\section{Nomenclature \\ wt. \% Weight percentage \\ SEM Scanning electron microscope \\ $V H N \quad$ Vicker's Hardness number \\ SWR Specific wear rate \\ $M M L \quad$ Mechanical mixed layer \\ $\mathrm{Ha}$ hardness of the abrasive particle \\ Hs hardness of the surface}

\section{References}

Aldas, K. \& Mat, M.D., 2005. Experimental and theoretical analysis of particle distribution in particulate metal matrix composites, Journal of Materials Processing Technology, Vol 160, No.3, pp. 289-295.

Archard, J., 1953. Contact and rubbing of flat surfaces, Journal of Applied Physics, Vol24, No. 8, pp. 981-988.

Alpas, A.T. \& Zhang, J., 1992. Effect of SiC particulate reinforcement on the dry sliding wear of aluminium-silicon alloys (A356), Wear, Vol 155, No.1, pp. 83-104.

Agarwal, B.D., Broutman, L.J. \& Chandrashekhara, K., 2017. Analysis and performance of fiber composites, John Wiley \& Sons.

Basavarajappa, S., Chandramohan, G., Subramanian, R. \& Chandrasekar, A., 2006. Dry sliding wear behaviour of Al 2219/SiC metal matrix composites, Materials Science-Poland, Vol24, No. 2/1, pp. 357-366.

Baradeswaran, A. and Perumal, A.E., 2013. Influence of B4C on the tribological and mechanical properties of Al 7075-B4C composites", Composites Part B: Engineering, Vol54, pp.146-152.

Bera, T., Acharya, S.K. \& Sutradhar, G.,2017. Solid particle erosion behaviour of cenosphere reinforced LM6 (Al-Si12) matrix alloy composites, International Journal of Materials Engineering Innovation, Vol 8, No. 3-4, pp. 206-221.

Bera, T. \&Acharya, S.K., 2017. Utilization of fly ash cenosphere as reinforcement for abrasive wear behaviour of LM6 Al alloy metal matrix composites, Iranian Journal of Science and Technology, Transactions of Mechanical Engineering, pp. 1-8.

Canute, X. and Majumder, M.C., 2018. Mechanical and tribological behaviour of stir cast aluminium/boron carbide/fly ash composites, Journal of Engineering Science and Technology, Vol 13, No. 3, pp.755-777.

Das, S., Mondal, D.P., Sawla, S. \&Ramakrishnan, N., 2008. Synergic effect of reinforcement and heat treatment on the two body abrasive wear of an Al-Si alloy under varying loads and abrasive sizes, Wear, Vol264, No.1-2, pp. 47-59.

Deuis, R.L., Subramanian, C. \& Yellup, J.M.,1996. Abrasive wear of aluminium composites-a review, Wear, Vol 201, No. 1-2, pp. 132-144.

Ghomashchi, M. R., \&Vikhrov, A., 2000. Squeeze casting: an overview, Journal of Materials Processing Technology, Vol 101, No.1, pp. 1-9.

Ghosh, P.K. \& Ray, S.,1988. Influence of process parameters on the porosity content in $\mathrm{Al}(\mathrm{Mg})--\mathrm{Al}_{2} \mathrm{O}_{3}$ cast particulate composite produced by vortex method, Transactions of the American Foundrymen's Society, Vol96, pp. 775-782.

https://en.wikipedia.org/wiki/cenosphere.

http://www.cast-alloys.com/products/lm_chart.htm.

Hashim, J., Looney, L. \& Hashmi, M.S.J., 2001. The enhancement of wettability of SiC particles in cast aluminium matrix composites, Journal of Materials Processing Technology, Vol119, No.1, pp. 329-335.

Hanumanth, G.S. \& Irons, G.A., 1993. Particle incorporation by melt stirring for the production of metal-matrix composites, Journal of Materials Science, Vol28, No. 9, pp. 2459-2465.

Jiang, J., Stott, F.H. \& Stack, M.M., 1995. A mathematical model for sliding wear of metals at elevated temperatures. Wear, Vol181, pp. 20-31.

Kalaiselvan, K.; Murugan, N.; and Parameswaran, S., 2011. Production and characterization of Al 6061-B4C stir composite, Materials and Design, Vol32, No. 7, pp. 4004-4009.

Kok, M., 2000. Production of metal matrix $\left(\mathrm{Al}_{2} \mathrm{O}_{3}\right.$-reinforced) composite materials and investigation of their machinability by ceramic tools, PhD Thesis, Elazig: Firat University.

Kwok, J.K.M., Goh, H.S. \& Lim, S.C.,1994. Effects of mechanical alloying on the friction and wear characteristics of Al-4.5 Cu$15 \mathrm{SiC}$ particulate composites, In Proc. 4th Int. Tribology Conf. Austrib, Vol8, pp. 241-247.

Lashgari, H.R., Emamy, M., Razaghian, A. and Najimi, A.A., 2009. The effect of strontium on the microstructure, porosity and tensile properties of A356-10\% B4C cast composite, Materials Science and Engineering: A, Vol 517, No.1-2, pp.170-179.

Lim, S.C., Liu, Y. \& Tong, M.F., 1992. The effects of sliding condition and particle volume fraction on the unlubricated wear of aluminum alloy-SiC particle composites. In Proc. Conf. on 'Processing properties and application of metallic and ceramic materials', Birmingham, UK, pp. 485-490. 
Moustafa, S.F., 1995. Wear and wear mechanisms of Al-22\% Si/A12O3f composite. Wear, Vol185, No. 1-2, pp. 189-195.

Onat, A., Akbulut, H. \&Yilmaz, F., 2007. Production and characterization of silicon carbide particulate reinforced aluminiumcopper alloy matrix composites by direct squeeze casting method", Journal of Alloys and Compounds, Vol436, No. 1-2, pp. 375382.

Onat, A., 2010. Mechanical and dry sliding wear properties of silicon carbide particulate reinforced aluminium-copper alloy matrix composites produced by direct squeeze casting method. Journal of Alloys and Compounds, Vol489, No.1, pp. 119-124.

Prabu, S.B., Karunamoorthy, L., Kathiresan, S. and Mohan, B., 2006. Influence of stirring speed and stirring time on distribution of particles in cast metal matrix composite, Journal of Materials Processing Technology, Vol 171, No. 2, pp.268-273.

Rohatgi P. K., 1994. Low-cost, fly-ash-containing aluminum-matrix composites, Journal of The Minerals, Metals \& Materials Society, Vol46, No.11, pp. 55-59.

Rana, F. \& Stefanescu, D.M.,1989.“Friction properties of Al-1.5 Pct Mg/SiC particulate metal-matrix composites, Metallurgical Transactions A, Vol20, No. 8, pp.1564-1566.

Wang, A. \& Rack, H.J.,1991. Transition wear behavior of SiC-particulate-and SiC-whisker-reinforced 7091 Al metal matrix composites, Materials Science and Engineering: A, Vol14, No. 2, pp. 211-224.

Sahin, Y., \& Özdin, K., 2008. A model for the abrasive wear behaviour of aluminium based composites, Materials \& Design, Vol29, No. 3, pp. 728-733.

Subramanian, C., 1991. Effects of sliding speed on the unlubricated wear behaviour of Al-12.3 wt. \% Si alloy, Wear, Vol151, No. 1, pp. 97-110.

Saka, N. \& Karalekas, D.P., 1985. Friction and wear of particle-reinforced metal-ceramic composites, Wear of Materials, pp.784.

Sukumaran, K., Pillai, R.M., Pillai, S.G.K. \& Pai, B.C.,2004. Squeeze casting: a novel metal processing technique”, Indian Foundry Journal, Vol 50, No. 2, pp. 21-28.

Sun, Y., Lyu, Y., Jiang, A. and Zhao, J., 2014. Fabrication and characterization of aluminum matrix fly ash cenosphere composites using different stir casting routes, Journal of Materials Research, Vol29, No.2, pp.260-266.

Sukumaran, K., Ravikumar, K.K., Pillai, S.G.K., Rajan, T.P.D., Ravi, M., Pillai, R.M. \& Pai, B.C.,2008. Studies on squeeze casting of Al 2124 alloy and 2124-10\% SiCp metal matrix composite, Materials Science and Engineering: A, Vol490, No.1-2, pp. 235-241.

Yue, T.M. \& Chadwick, G.A., 1996. Squeeze casting of light alloys and their composites, Journal of Materials Processing Technology, Vol 58, No. 2-3, pp. 302-307.

Zhenfang, Z., Liangchi, Z. \&Yiu-Wing, M., 1994. Modelling friction and wear of scratching ceramic particle-reinforced metal composites. Wear, Vol176, No. 2, pp. 231-237.

\section{Biographical notes}

TanusreeBera is a research scholar in department of mechanical at NIT Rourkela with Machine design specialization, working on Tribological studies of Aluminium metal matrix composites. Her areas of interests are the Casting Technology, Natural Fiber Reinforced Polymer Composites, Metal matrix Composites, as well as Tribology. She has worked as the Assistant Professor in Mechanical Engineering Department at C.V. Raman college of Engineering, Odisha, India, and served the college in several other administrative positions. She received her B.Tech. degree in Mechanical Engineering from Gandhi Institute of Engineering and Technology (GIET Gunupur ), Odisha, India, and M.Tech. degree in Mechanical engineering with a specialization in production engineering from Veer Surendra Sai University of Technology (VSSUT)Burla, Odisha, India.

Prof. Dr. S.K.Acharya joined as lecturer in Mechanical Engineering department R.E.C Rourkela now NIT Rourkela in 1987. He did His PhD from Sambalpuruniversity, Odisha, India in the year 2001. Presently he is working as a professor in the same department. His area of interest includes Tribology of composite materials, design of machine elements etc. He has produced $10 \mathrm{PhD}$ in the field of polymer composite and has guided more than $50 \mathrm{M}$. Tech students. $\mathrm{He}$ has more than 75 international and about 50 national publications in different journals. He is Fellow and Life member to different societies like TSI, Instituitional of Engineers (India) ISTM, FICEr etc. He has visited Clausthal University of Technology, Germany for specialized training on Shot peening technology and worked with Prof. Lothar Wagner.

Prof. Dr. Goutam Sutradhar is the director at NIT Manipur. He received his PhD from the BIT Mesra University. His research interests include- the Casting Technology, Micro \& Nano Metal Matrix Composites, Natural Fiber Reinforced Polymer Composites, Characterization of Powder Metallurgy, Components and critical communication. He has 5 years' Experience in Industry and 25 years experiences in Teaching \& Research Vast experiences in Process \& Product Development of Industrial Castings like Railways, Automobile and Textile Machineries. He has published books such as Principles of Foundry Process Design, Design \& Manufacturing -An Integrated Approach. He has been awarded by Indian Foundry Journal - 2011-2012 for best paper in the year 2012, Institute of Engineers (India) for the Year of merit award in 1995-96 in the year 1995, DST, New Delhi for SERC Visiting Fellowship in the year 1995.

Received August 2018

Accepted October 2018

Final acceptance in revised form November 2018 